\title{
Comparative exergy analysis of direct alcohol fuel cells using fuel mixtures
}

\author{
Teresa J. Leo - Miguel A. Raso Emilio Navarro Emilia Sánchez-de-la-Blanca
}

\begin{abstract}
A B S T R A C T
Within the last years there has been increasing interest in direct liquid fuel cells as power sources for portable devices and, in the future, power plants for electric vehicles and other transport media as ships will join those applications. Methanol is considerably more convenient and easy to use than gaseous hydrogen and a considerable work is devoted to the development of direct methanol fuel cells. But ethanol has much lower toxicity and from an ecological viewpoint ethanol is exceptional among all other types of fuel as is the only chemical fuel in renewable supply. The aim of this study is to investigate the possibility of using direct alcohol fuel cells fed with alcohol mixtures. For this purpose, a comparative exergy analysis of a direct alcohol fuel cell fed with alcohol mixtures against the same fuel cell fed with single alcohols is performed. The exergetic efficiency and the exergy loss and destruction are calculated and compared in each case. When alcohol mixtures are fed to the fuel cell, the contribution of each fuel to the fuel cell performance is weighted attending to their relative proportion in the aqueous solution. The optimum alcohol composition for methanol/ethanol mixtures has been determined.
\end{abstract}

\section{Introduction}

Fuel cells are known for the efficient conversion of chemical energy stored in fuels and oxidants into electricity. In particular, low temperature fuel cells represent a promising power source for a variety of applications depending on the fuel used. At present, the hydrogen-oxygen polymer electrolyte fuel cells have reached a satisfactory degree of development, but hydrogen has evident drawbacks in transport, storage and manipulation [1,2]. Within the last years there has been increasing interest in direct liquid fuel cells as power sources for portable devices and, in the future, power plants for electric vehicles and other transport media will join these applications [2,3]. Methanol is considerably more convenient and easy to use as a fuel than gaseous hydrogen and a considerable work is devoted to the development of direct methanol fuel cells [4]. But despite the relatively higher electrochemical activity of methanol compared to the other possible liquid fuels, methanol is toxic for human beings. Ethanol is considered a promising fuel for direct alcohol fuel cells since it has much lower toxicity than methanol is considered renewable and can be easily produced in great quantity by the fermentation of biomass [5,6]. Besides, the ethanol specific energy content is higher than that of methanol. Nevertheless the electrochemical oxidation features of ethanol make the performance of direct ethanol fuel cell to be rather low.
The objective of this study is to investigate the possibility of using direct alcohol fuel cells fed with alcohol mixtures. For this purpose, and as a previous stage to performing experimental measurements, a comparative exergy analysis of a direct alcohol fuel cell fed with alcohol mixtures against the same fuel cell fed with single alcohols is performed. Methanol and ethanol are selected as fuels. The exergy loss and destruction are calculated as a whole and compared in each case at typical operating conditions. The exergetic efficiency of the corresponding fuel cell system is calculated also for each composition of the mixture. In this work, the contribution to the fuel cell performance of each fuel in the mixture is assumed to be directly related to its respective proportion in the aqueous solution. In order to simplify the models used to describe the fuel cell performance when fed with a unique alcohol aqueous solution (methanol or ethanol) the commonly used assumptions in steady state fuel cell models are adopted in this study [7-9].

From the results obtained with the simplified model proposed for the fuel mixture, the optimum alcohol composition can be determined.

The reactions taking place at the electrodes and the overall current-producing reaction of methanol in the fuel cell are as follows:

$$
\begin{aligned}
& \text { Anode: } \mathrm{CH}_{3} \mathrm{OH}+\mathrm{H}_{2} \mathrm{O} \rightarrow \mathrm{CO}_{2}+6 \mathrm{H}^{+}+6 \mathrm{e}^{-} \\
& \text {Cathode : } \frac{3}{2} \mathrm{O}_{2}+6 \mathrm{H}^{+}+6 \mathrm{e}^{-} \rightarrow 3 \mathrm{H}_{2} \mathrm{O} \\
& \text { Overall: } \mathrm{CH}_{3} \mathrm{OH}+\frac{3}{2} \mathrm{O}_{2} \rightarrow \mathrm{CO}_{2}+2 \mathrm{H}_{2} \mathrm{O}
\end{aligned}
$$




Nomen
$A_{v, a j} j_{0}^{r e f}$
$c_{i}$
$E$
$E^{0}$
$\dot{E}_{x}$
$e_{x}$
$F$
$j$
$j_{0}$
$j_{l i m}$
$j_{w}$
$l$
$n_{d}$
$\dot{n}_{i n}$
$\dot{Q}$
$R$
$r_{C}$
$S$
$S_{i}$
$T$
$V$
$V_{i}$
$w^{a}$
$W$
$y_{E}$
$y_{M}$
$z$

reference exchange current density times specific surface area on anode

reactive concentrations in catalytic layer

Nernst potential under operating conditions

standard potential

exergy flow rate

molar flow exergy

Faraday constant

current density

exchange current density

limiting current density

intermediate variable in the calculus of $r_{C}$

layer thickness

electrosmotic drag coefficient

input molar flow rate

heat rate

gas constant, membrane plus contact resistance

times area

alcohol crossover rate

total active area of the fuel cell

active area occupied by fuel $i$

absolute temperature

output voltage of the fuel cell

output voltage for the fuel cell fed with pure $i$ fuel

water concentration in the anode catalytic layer

power

molar proportion of ethanol in the alcohol mixture molar proportion of methanol in the alcohol mixture number of electrons interchanged in the electrode semireaction

\section{Subscripts}

D destruction

E ethanol

M methanol

a anode, anodic

alc alcohol

amb ambient

$b \quad$ backing layer

c cathode, cathodic, catalytic

cross crossover

in total input

loss losses

$m$ polymeric membrane

opt optimum, corresponding to power maximum or to minimum exergy loss and destruction

out total output

\section{Superscripts}

E ethanol

M methanol

a anode, anodic

c cathode, cathodic

ref reference

\section{Greek letters}

$\alpha \quad$ transfer coefficient

$\beta \quad$ intermediate variable in the calculus of $r_{C}$

$\gamma \quad$ reaction order

$\varepsilon \quad$ exergetic efficiency

$\eta \quad$ overpotential

$\eta_{\text {act }} \quad$ activation overpotential $\eta_{\text {conc }} \quad$ concentration overpotential

$\eta_{\text {ohmic }}$ ohmic overpotential

$v_{i}$

stoichiometric coefficients

and the corresponding to ethanol:

Anode $: \mathrm{C}_{2} \mathrm{H}_{5} \mathrm{OH}+3 \mathrm{H}_{2} \mathrm{O} \rightarrow 2 \mathrm{CO}_{2}+12 \mathrm{H}^{+}+12 \mathrm{e}$

Cathode $: 3 \mathrm{O}_{2}+12 \mathrm{H}^{+}+12 \mathrm{e}^{-} \rightarrow 6 \mathrm{H}_{2} \mathrm{O}$

Overall : $\mathrm{C}_{2} \mathrm{H}_{5} \mathrm{OH}+3 \mathrm{O}_{2} \rightarrow 2 \mathrm{CO}_{2}+3 \mathrm{H}_{2} \mathrm{O}$

\section{Exergy analysis of a fuel cell system using fuel mixtures}

In this work, a comparative exergy study of a fuel cell system directly fed with an aqueous methanol solution, an aqueous ethanol solution or aqueous methanol-ethanol mixtures at different proportions is carried out. In each case, the exergetic efficiency and the exergy loss and destruction are calculated as a function of the relative proportion of methanol and of the operation current density.

\subsection{General assumptions}

To develop this study the molar flow rate of alcohol $\dot{n}_{i \pi}=\dot{n}_{M, i n}+$ $\dot{n}_{E, \text { in }}$ entering the fuel cell system is kept constant and pure oxygen is used as oxidant. Then, the proportion of methanol in the mixture $y_{M}$ can be expressed as

$y_{M}=\frac{\dot{n}_{M, i n}}{\dot{n}_{i n}}$

and that of ethanol $y_{E}=\dot{n}_{E, i n} / \dot{n}_{i n}$. Therefore $y_{M}+y_{E}=1$.

The commonly used assumptions in steady state fuel cell models are adopted in this study:

- All parameters are time-independent.

- All gases are ideal gases.

- Liquid mixtures behave as ideal mixtures.

- Mass flow is laminar flow.

- Temperature distribution is uniform.

- The waste heat of the cells is not recovered in either case.

- Kinetic and potential exergies are neglected.

- The amount of water consumed by humidifying the reactants streams is negligible.

\subsection{Modelling the $V-j$ behaviour of a direct alcohol fuel cell using fuel mixtures}

The $V-j$ behaviour of a direct alcohol fuel cell fed with an aqueous alcohol solution can be modelled at different degrees of complexity. To explain the polarization curves of direct methanol DMFC and direct ethanol DEFC fuel cells, several models at different stages of complexity, with more or less success, have been proposed in the literature $[4,8,10,11]$. A problem arises when the task of modelling the $V-j$ behaviour of an aqueous solution alcohol mixture feeding a direct alcohol fuel cell is undertaken. This task can be divided into successive steps of increasing complexity. As a first step, a very simple model is proposed in this work.

\subsubsection{A simple $V$-j model for fuel mixtures}

The behaviour of a fuel cell operating with a fuel mixture can be modelled taking as a reference the behaviour of the fuel cell when it is fed by each of the fuels separately. A very simple way of taking into account the influence of the electrooxidation of each 
alcohol on the fuel cell performance can be accomplished by making the assumption that each alcohol reacts on a fraction of the total active area $S$ which is proportional to the relative molar proportion of alcohol $y$ in the mixture. That is, the corresponding methanol and ethanol active areas can be assumed as $S_{M}=y_{M} S$ and $S_{E}=y_{E} S$, respectively. Thus the fuel cell voltage-current density curve, when the fuel cell is fed by a fuel mixture of methanol and ethanol, can be modelled at a first approximation as

$V=y_{M} V_{M}+y_{E} V_{E}$

where $V_{M}$ and $V_{E}$ represent the $V$ - $j$ behaviour of aqueous methanol and ethanol solutions if alone, respectively. As both alcohols and their mixtures are studied when operating in the same fuel cell, the same polarization curve model should be adopted for both alcohols.

\subsubsection{The polarization curve when the fuel is a single alcohol. A unique model for methanol and ethanol}

The general expression of a fuel cell polarization curve can be written as

$V=E-\eta_{a c t, a}-\eta_{a c t, c}-\eta_{\text {conc }, a}-\eta_{\text {conc, } c}-\eta_{\text {ohmic }}$

where $E$ stands for the Nernst potential in the operating conditions:

$E=E^{0}+\frac{R T}{z_{a} F} \ln \left(\frac{c_{\mathrm{CO}_{2}}^{\nu_{\mathrm{CO}}}}{c_{a l c} c_{\mathrm{O}_{2}}^{\nu_{\mathrm{O}_{2}}}}\right)$

When the alcohol is methanol $v_{\mathrm{CO}_{2}}=1, v_{\mathrm{O}_{2}}=3 / 2$ and $z_{a}=6$, but if the fuel is ethanol $v_{\mathrm{CO}_{2}}=2, v_{\mathrm{O}_{2}}=3$ and $z_{a}=12$, as derived from Eqs. (1) and (2), respectively. Concentration of saturated gaseous oxygen in the inlet flow is calculated as $c_{h}^{c}=\left(p_{\mathrm{O}_{2, \text { in }}}-p_{\text {sat }}(T)\right) / R T$ and solubilities of $\mathrm{O}_{2}$ and $\mathrm{CO}_{2}$ in water are taken to calculate $\mathrm{CO}_{2}$, and $\mathrm{C}_{\mathrm{CO}_{2}}$ [12], respectively. Alcohol concentration in the catalytic layer $c_{a l c}$ is calculated as in [13], but multiplied by $\left(1-r_{c}\right)$ in order to take into account the crossover. The crossover rate $r_{c}$ is calculated as proposed in [11]:

$r_{c}=\frac{\left(j_{\lim }^{a}-j\right)\left(\beta+n_{d} j / j_{w}\right)}{j+j_{\lim }^{c}\left(\beta+n_{d} j / j_{w}\right)}, \quad \beta=\frac{D_{m} l_{b}^{a}}{D_{b}^{a} l_{m}}, \quad j_{w}=F D_{b}^{a} \frac{w^{a}}{l_{b}^{a}}$

being $w^{a}$ the water molar concentration and $j_{\lim }^{a}, j_{\text {lim }}^{c}$ stand for the anode and cathode limiting current densities respectively:

$j_{\lim }^{a}=z_{a} F \frac{D_{b}^{a} c_{h}^{a}}{l_{b}^{a}}, \quad j_{\lim }^{c}=4 F \frac{D_{b}^{c} c_{h}^{c}}{l_{b}^{c}}$

where $c_{h}^{a}$ stands for the inlet alcohol concentration, $l_{b}^{a}, l_{b}^{c}$ are the thicknesses of the anode and the cathode backing layers, respectively, and $D_{b}^{a}, D_{b}^{c}$ represent the diffusion coefficient of alcohol and oxygen in their respective backing layers.

The anodic [11,14] and cathodic [11,15] activation overvoltages as a function of the exchange current density $j_{0}$ and the parameter $\alpha$ have the following expressions:

$\eta_{a c t, a}=\frac{R T}{z_{a} \alpha_{a} F} \ln \frac{j}{j_{0, a}}, \quad \eta_{a c t, c}=\frac{R T}{z_{c} \alpha_{c} F} \ln \frac{j}{j_{0, c}}$

The anode exchange current density $j_{0, a}$ can be estimated as a function of the anode reaction order $\gamma_{a}$ and the alcohol concentration in the catalytic layer $c_{a l}$, by means of the following expression derived from [16-18]:

$j_{0, a}=I_{c}\left(\frac{c_{a l c}}{c_{a l c}^{r e f}}\right)^{\gamma_{a}} A_{v, a j} j_{0}^{r e f}$

where $A_{v, a} j_{0}^{\text {ref }}$ represents a reference exchange current density times specific surface area on anode. Values of $j_{0, c}$ have been taken from [15].

The concentration overvoltage is calculated following the expressions given in [19]:

$\eta_{\text {conc }, a}=\frac{R T}{z_{a} F} \ln \left(\frac{j_{\lim }^{a}}{j_{\lim }^{a}-j-j_{\text {cross }}}\right)$,

$\eta_{\text {conc }, c}=\frac{R T}{z_{c} F} \ln \left(\frac{j_{\text {lim }}^{c}}{j_{\text {lim }}^{c}-j-j_{\text {cross }}}\right)$

where $j_{\text {lim }}$ and the flux of alcohol through the membrane, expressed in current density units, $j_{\text {cross }}$ are calculated as in [11].

The ohmic overpotential is expressed as $\eta_{\text {ohmic }}=R j$, where $R$ stands for the sum of membrane and contact resistance times area.

Up to the authors knowledge, references dealing with experimental measurements using a unique direct alcohol fuel cell fed either with methanol or ethanol, are very scarce [9,20]. Nafion 115 is used in [20] and Nafion 117 in [9]. Higher current density values are reached in [20]. Then, the methanol and ethanol fuel cell parameters to be used in this work, where a unique fuel cell is considered for every fuel under study (methanol, ethanol, methanol-ethanol mixtures), have been obtained by fitting the experimental data given in [20] to the above described model.

The fitted parameters of the model are those directly affected by the type of fuel used. They are the anode reaction order $\gamma_{a}$, the membrane diffusion coefficient $D_{m}$, the anode backing layer diffusion coefficient $D_{b}^{a}$, the anode parameter $\alpha_{a}$, and the membrane and contact resistance times area $R$.

The fixed parameters assumed in the model, for methanol and ethanol, are shown in Table 1.

\subsection{Exergy analysis}

The exergy balance at steady state can be written in a general way as

$\dot{E}_{x, i n}=\dot{E}_{x, o u t}+\dot{E}_{x, D}+\dot{E}_{x, l o s s}$

Table 1

Assumed parameter values for methanol and ethanol.

\begin{tabular}{|c|c|c|}
\hline Parameter & Methanol & Ethanol \\
\hline Standard Nernst potential $E^{0}$ & 1.214 & 1.146 \\
\hline Number of electrons considered in the anodic reaction $z_{a}$ & 6 & 12 \\
\hline Membrane thickness $I_{m}(\mathrm{~cm})$ & $0.0125[17]$ & $0.0125[17]$ \\
\hline Backing layer thickness (anode and cathode) $l_{b}(\mathrm{~cm})$ & $0.026[17]$ & $0.026[17]$ \\
\hline Catalyst layer thickness (anode and cathode) $l_{c}(\mathrm{~cm})$ & $0.0020[17]$ & $0.0020[17]$ \\
\hline Cathode transfer coefficient $\alpha_{c}$ & $1[10,17]$ & $1[10,17]$ \\
\hline Electrosmotic drag coefficient $n_{d}$ & $3.16[10]$ & $3.16[10]$ \\
\hline Diffusion coefficient of oxygen in the cathode backing layer $D_{b}^{c}\left(\mathrm{~cm} \mathrm{~s}^{-1}\right)$ & 0.338 [19] & $0.338[19]$ \\
\hline Order of reaction (cathode) $\gamma_{c}$ & $1[5,17]$ & $1[5,17]$ \\
\hline Anode reference exchange current density times specific surface area $A_{v, j} j_{0}^{\text {ref }}\left(\mathrm{Acm}^{-3}\right)$ & $0.100 \exp \left[\frac{35570}{R}\left(\frac{1}{353}-\frac{1}{T}\right)\right][17]$ & $0.179 \exp \left[\frac{39332}{R}\left(\frac{1}{353}-\frac{1}{T}\right)\right][10]$ \\
\hline Cathode exchange current density $j_{0, c}\left(\mathrm{Acm}^{-2}\right)$ & $1.87 \times 10^{-8}[15]$ & $1.87 \times 10^{-8}[15]$ \\
\hline
\end{tabular}


Table 2

Environmental reference state composition and chemical exergy of the compounds involved in this study $\left(T_{0}=298.15 \mathrm{~K} ; p_{0}=1 \mathrm{~atm}\right)[21,22]$.

\begin{tabular}{llr}
\hline Species & Dead state mole fraction & Chemical exergy $\left(\mathrm{kJ} \mathrm{mol}^{-1}\right)$ \\
\hline $\mathrm{N}_{2}$ & 0.77251 & 0.640 \\
$\mathrm{O}_{2}$ & 0.20555 & 3.922 \\
$\mathrm{CO}_{2}(\mathrm{~g})$ & 0.00029 & 20.163 \\
$\mathrm{H}_{2} \mathrm{O}(\mathrm{g})$ & 0.02165 & 9.502 \\
$\mathrm{H}_{2} \mathrm{O}(\mathrm{l})$ & & 0.914 \\
$\mathrm{CH}_{3} \mathrm{OH}(\mathrm{l})$ & & 718.369 \\
$\mathrm{C}_{2} \mathrm{H}_{5} \mathrm{OH}(\mathrm{l})$ & & 1356.777 \\
\hline
\end{tabular}

$\dot{E}_{x, i n}=\sum_{i} \dot{n}_{i, i n} e_{x}+\dot{W}_{i n}+\sum_{i} \dot{Q}_{i, i n}\left(1-\frac{T_{a m b}}{T_{i}}\right)$

$\dot{E}_{x, \text { out }}=\sum_{i} \dot{n}_{i, o u t} e_{x}+\dot{W}_{\text {out }}+\sum_{i} \dot{Q}_{i, \text { out }}\left(1-\frac{T_{a m b}}{T_{i}}\right)$

where in general, $\dot{E}_{x, \text { in }}$ denotes the exergy entering the system with work, heat or incoming streams; $\dot{E}_{x, \text { out }}$ denotes the exergy leaving the system with work, heat or outgoing streams with a further use; $\dot{E}_{x, D}$ is associated with the destruction of exergy due to irreversibilities, and exergy loss $\dot{E}_{x, l o s s}$ represents the exergy associated with streams thrown to the ambient. The total exergy associated with a stream on a unit-of-mole basis is denoted by $e_{x}$.

Exergy loss and exergy destruction are calculated as a whole $\dot{E}_{X, l_{\text {loss }} D}$ in the fuel cell system as a function of the relative proportion of methanol $y_{M}$ in the fuel mixture and the operation current density.

Similarly, the exergetic efficiency $\varepsilon$ calculations are performed as a function of these two variables. It is calculated as follows:

$\varepsilon=\dot{n}_{i n} \frac{y_{M} z_{M} F\left[1-r_{c, M}(j)\right] V_{M}(j)+y_{E} z_{E} F\left[1-r_{c, E}(j)\right] V_{E}(j)}{\dot{E}_{x, i n}^{\text {alcohol }(a q)}+\dot{E}_{x, i n}^{\mathrm{O}_{2}}}$

The exergy of the aqueous fuel and the oxygen entering the fuel cell system is calculated by means of:

$\dot{E}_{x, i n}^{\text {alcohol }(a q)}=\dot{n}_{i n, M} e_{x, M}+\dot{n}_{i n, E} e_{x, E}+\dot{n}_{i n, \mathrm{H}_{2} \mathrm{O}} e_{x, \mathrm{H}_{2} \mathrm{O}}+\dot{n} R T \sum x_{i} \ln x_{i} ;$

$\dot{n}=\dot{n}_{i n, M}+\dot{n}_{i n, E}+\dot{n}_{i n, \mathrm{H}_{2} \mathrm{O}}$

and

$\dot{E}_{x, i n}^{\mathrm{O}_{2}}=\left(\dot{n}_{i n, M} v_{\mathrm{O}_{2}}^{M}+\dot{n}_{i n, E} v_{\mathrm{O}_{2}}^{E}\right) e_{x, \mathrm{O}_{2}}$

Reference environmental state used and chemical exergy of the substances involved are summarized in Table 2 [21,22].

\section{Results and discussion}

Aqueous solutions of methanol and ethanol mixtures have been used as fuel, being pure oxygen the oxidant. The relative methanol proportion in the alcohol mixture has been studied ranging from 0 to 1 . In all cases, a molar flow rate of $1 \mathrm{~mol} \mathrm{~s}^{-1}$ entering the fuel cell system and a total alcohol solution concentration of $1 \mathrm{M}$ has been considered.

\subsection{Polarization curves}

\subsubsection{A unique model for methanol and ethanol}

The fitting parameter values obtained for both methanol and ethanol are shown in Table 3. As said before, experimental data from a unique fuel cell fed with methanol or with ethanol have been fitted to the $V-j$ model described in Section 2.2.2. Operation temperature and concentration selected have been $75^{\circ} \mathrm{C}$ and $1 \mathrm{M}$, respectively. The results obtained seem to be very reasonable. As expected, methanol diffusivities in membrane and catalyst layer are
Table 3

Fitting parameters of the $V-j$ model used for methanol and ethanol.

\begin{tabular}{lll}
\hline Parameter & Methanol & Ethanol \\
\hline $\begin{array}{l}\text { Order of reaction (anode) } \gamma_{a} \\
\text { Diffusion coefficient of alcohol in } \\
\quad \text { membrane } D_{m}\left(\mathrm{~cm}^{2} \mathrm{~s}^{-1}\right)\end{array}$ & 0.862 & 0.895 \\
$\begin{array}{c}\text { Diffusion coefficient of alcohol in the } \\
\text { anode backing layer } D_{b}^{a}\left(\mathrm{~cm}^{2} \mathrm{~s}^{-1}\right)\end{array}$ & $1.45 \times 10^{-5}$ & $2.55 \times 10^{-6}$ \\
$\begin{array}{c}\text { Anode transfer coefficient }\left(75^{\circ} \mathrm{C}\right) \alpha_{a} \\
\text { Membrane and contact resistance } \\
\text { times active surface area } R\left(\Omega \mathrm{cm}^{2}\right)\end{array}$ & 0.145 & 0.034 \\
\hline
\end{tabular}

higher than those of ethanol. Anode transfer coefficient of methanol has a higher value than that of ethanol, which agrees well with the faster kinetics of methanol electrooxidation. Indeed, methanol membrane and contact resistance results lower than ethanol one, as already observed [9]. Polarization curves generated with the model described and the fitting parameters obtained for methanol and ethanol are shown in Fig. 1.

\subsubsection{A simple polarization curve model for methanol and ethanol mixtures}

The polarization curves corresponding to methanol and ethanol mixtures have been generated following Eq. (4). Fig. 2 shows the alcohol mixtures polarization curves that the simple model

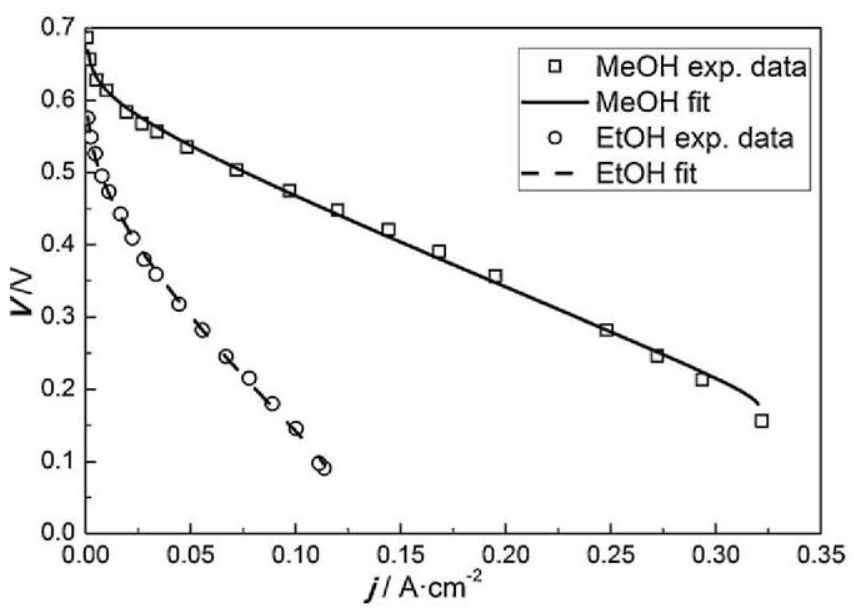

Fig. 1. Fitted polarization curves. Experimental data from [18] (total alcohol concentration $1 \mathrm{~mol} \mathrm{~L}^{-1}, \mathrm{~T}=348.15 \mathrm{~K}$ ).

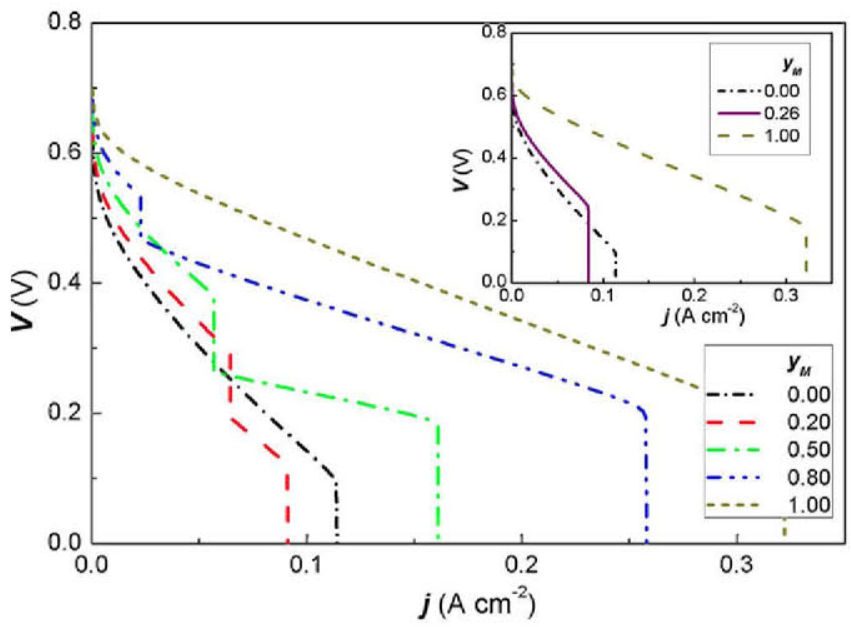

Fig. 2. Polarization curves obtained for aqueous mixtures of methanol and ethanol as fuel by using the simple mixture model proposed in this work. 


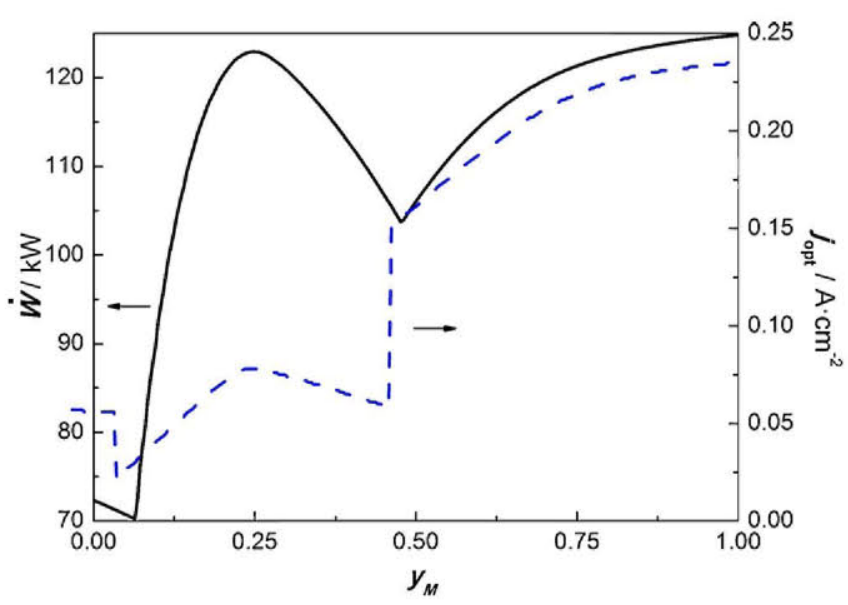

Fig. 3. The maximum power delivered by the fuel cell system and the current density at which each maximum power is obtained versus relative methanol proportion $y_{M}$ in the aqueous alcohol mixture.

proposed in this work gives rise to. Various relative methanol proportions, $y_{M}$, are represented. As can be seen in the figure, a better performance is predicted for increasing methanol proportions. The sharp steps observed when anode limiting current densities are attained can be partly attributed to the simplicity of the model. The curve at $y_{M}=0.26$ is represented in the inset. This curve, corresponding to an aqueous mixture of methanol and ethanol, exhibits a similar shape to that of aqueous methanol, $y_{M}=1$, and of aqueous ethanol, $y_{M}=0$, and is obtained when methanol and ethanol anodic limiting current densities have the same value, $j_{\text {lim }}^{a}=0.084 \mathrm{~A} \mathrm{~cm}^{-2}$. That is, at a methanol/ethanol molar proportion near to $30 / 70 \%$, the aqueous alcohol mixture behaves as an aqueous solution of a unique alcohol.

\subsection{Comparative exergy study}

Aqueous methanol and ethanol solutions have been used as fuel, being pure oxygen the oxidant.

\subsubsection{The exergy obtained: the power from fuel mixtures}

The maximum power delivered by the fuel cell system at each relative methanol proportion $y_{M}$ is graphically represented in Fig. 3 . In the same graph, the current density at which each maximum power is obtained, denominated optimum current density $j_{o p t}$, has been represented. Although the maximum power is found when $y_{M}=1$, that is, when the fuel is an aqueous methanol solution, a relative maximum is observed at $y_{M}=0.25$ and the corresponding $j_{\text {opt }}=0.076 \mathrm{~A} \mathrm{~cm}^{-2}$. This power is only $1.5 \%$ lower than the absolute

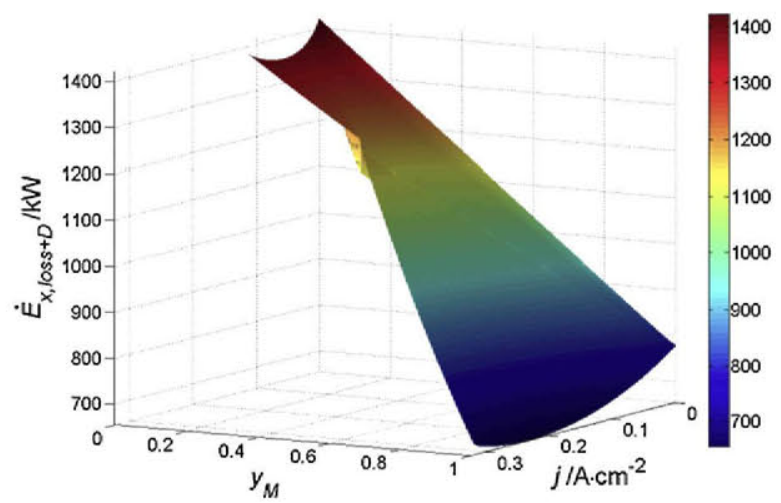

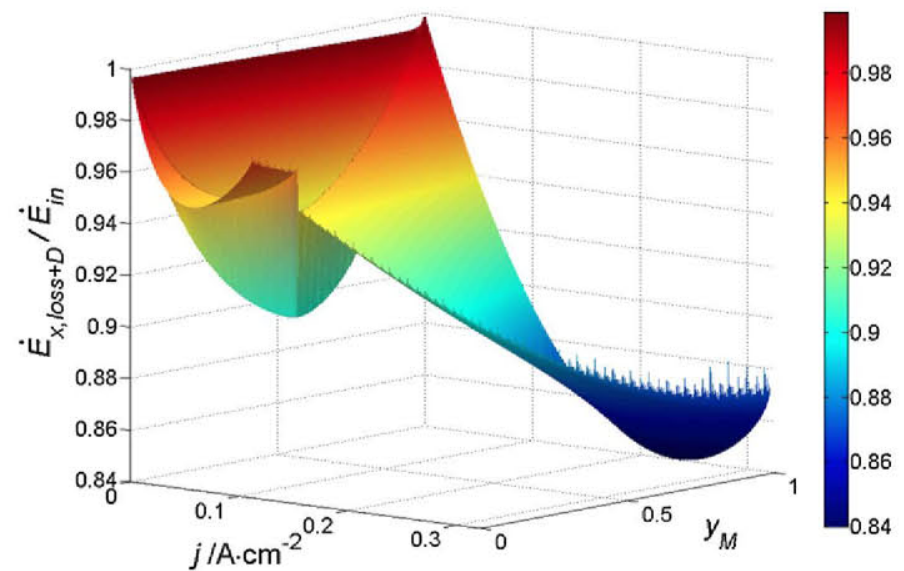

Fig. 5. The exergy loss and destruction divided by the exergy entering the system, $\dot{E}_{x, \text { loss }+D} / \dot{E}_{x, i n}$, at each relative methanol proportion $y_{M}$ represented against $y_{M}$ and $j$.

maximum value, which suggests that to investigate the possibility of using a "flexible" fuel cell can yield interesting results.

\subsubsection{The exergy loss and destruction for fuel mixtures}

The total exergy loss and destruction of the fuel cell system is represented in Fig. 4 as a function of $y_{M}$ and $j$. As expected, the higher values are obtained when the fuel is ethanol whereas the lower exergy loss and destruction values are observed with methanol. Nevertheless, in the region at about $y_{M}=0.30$ a change of trend is observed, i.e., the total exergy loss and destruction diminishes more rapidly from this proportion onwards. Fig. 4 shows this region in detail. This change of trend appears near to the point where the relative maximum of power is observed, see Fig. 3.

Indeed, if the relative exergy loss and destruction at each $y_{M}$, defined as the exergy loss and destruction divided by the exergy entering the system $\dot{E}_{x, l o s s+D} / \dot{E}_{x, i n}$, is represented against $y_{M}$ and $j$, Fig. 5, a minimum is observed at $y_{M}=0.29$ and the corresponding $j_{\text {opt }}=0.077 \mathrm{Acm}^{-2}$.

\subsubsection{The exergetic efficiency}

The maximum exergetic efficiency values obtained at each methanol relative proportion $y_{M}$ are represented in Fig. 6. Again, although the absolute maximum corresponds to the case in which the fuel cell is fed with aqueous methanol solution, a relative maximum is observed when a methanol-ethanol aqueous mixture with $y_{M}=0.29$ is used. The corresponding optimum current density is located at about $0.08 \mathrm{~A} \mathrm{~cm}^{-2}$.

Again, this fact suggests that the possibility of using a "flexible" fuel cell can be a promising research field.

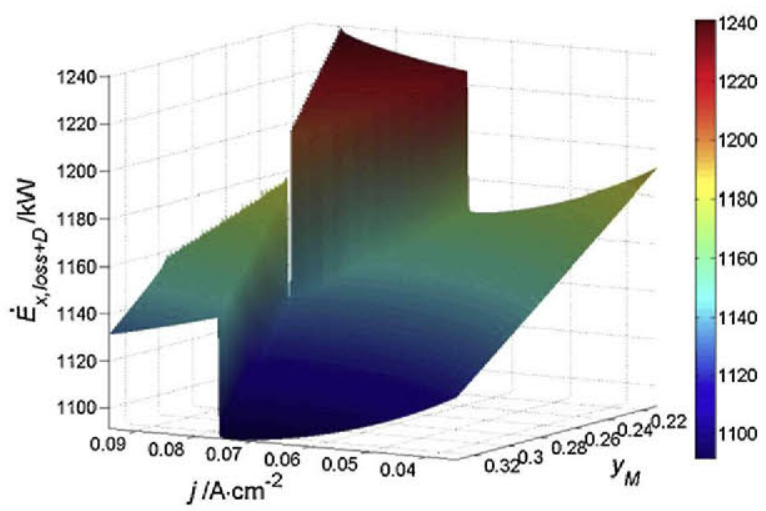

Fig. 4. (a) The total exergy loss and destruction of the fuel cell system as a function of $y_{M}$ and $j$. (b) The region where a change of trend is observed is shown in detail. 


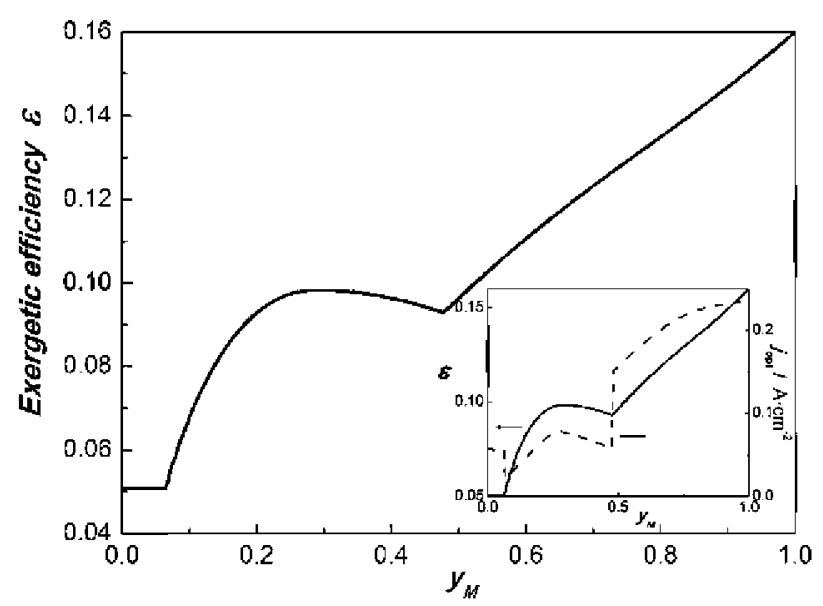

Fig. 6. The maximum exergetic efficiency value obtained at each relative methanol proportion $y_{M}$. The inner figure shows the current density value at which each maximum is obtained.

\section{Conclusions}

To investigate the possibility of using direct alcohol fuel cells fed with alcohol mixtures, an exergy analysis of a direct alcohol fuel cell fed with methanol/ethanol aqueous solutions at different molar proportions has been performed.

The exergy loss and destruction and the exergetic efficiency are calculated as a function of the relative methanol proportion and the current density. For this, a simple mathematical model of the fuel performance has been proposed as a first step. Each alcohol contributes to the cell voltage proportionally to its concentration in the fuel mixture. With this model, there is a methanol/ethanol molar proportion, near $30 / 70 \%$, for which the aqueous solution of alcohols mixture: (a) behaves as an aqueous solution of a unique alcohol, (b) shows a relative maximum of power, (c) presents a relative minimum of exergy loss and destruction and (d) gives a relative maximum of exergetic efficiency.

The main feature of this model is that an optimum operation point is predicted for a fuel consisting of mixtures of fuels. This fact allows expecting a singular behaviour of direct alcohol fuel cells fed with alcohol mixtures with an appreciably low content in methanol. From all these features, it can be concluded that studying the possibility of feeding a fuel cell with fuel mixtures can be a very promising research field.

\section{Acknowledgements}

This work has been financially supported by the Spanish Ministerio de Ciencia y Tecnología in the frame of the Project Code $\mathrm{N}^{\circ}$ ENE2007-67584-C03-03ALT. The authors gratefully acknowledge Dr. E. Mora for his help.

\section{References}

[1] A. Léon (Ed.), Hydrogen Technology Mobile and Portable Applications, Springer-Verlag, Berlin, 2008.

[2] V.S. Bagotsky, Fuel Cells, Problems and Solutions, J. Wiley \& Sons, Pennington, 2009, pp. 73-91.

[3] R. Rashidi, I. Dincer, G.F. Naterer, P. Berg, J. Power Sources 187 (2009) 509-516.

[4] A.A. Kulikovsky, Electrochem. Commun. 4 (2002) 939-946.

[5] D. Hotza, J.C. Diniz da Costa, Int. J. Hydrogen Energy 33 (2008) 4915-4935.

[6] E. Gnansounou, A. Dauriat, Bioresour. Technol. 101 (2010) 4980-4991.

[7] A. Ishihara, S. Mitsushima, N. Kamiya, K. Ota, J. Power Sources 126 (2004) $34-40$.

[8] L. Xianglin, H. Yaling, Y. Benhao, M. Zheng, L. Xiaoyue, J. Power Sources 178 (2008) 344-352.

[9] T.J. Leo, M.A. Raso, E. Navarro, E. Sánchez de la Blanca, M. Villanueva, B. Moreno, Int. J. Hydrogen Energy (2010), doi:10.1016/j.ijhydene.2010.02.115.

[10] G.M. Andreadis, A.K.M. Podias, P.E. Tsiakaras, J. Power Sources 194 (2009) 397-407.

[11] A.A. Kulikovsky, Electrochem. Commun. 5 (2003) 1030-1036.

[12] D.R. Lide, CRC Handbook of Chemistry and Physics, 87th ed., 2006-2007, pp. 8-84.

[13] H. Pramanik, S. Basu, Chem. Eng. Process. (2009), doi:10.1016/j.cep. 2009.10.015.

[14] Y. He, X. Li, Z. Miao, Y. Liu, Appl. Therm. Eng. 29 (2009) 1998-2008.

[15] A. Parthasarathy, S. Srinivasan, A.J. Appleby, C.R. Martin, J. Electrochem. Soc 139 (1992) $2530-2537$.

[16] C. Xu, A. Faghri, Int. J. Heat Mass Transf. 53 (2010) 1951-1966.

[17] C. Xu, T.S. Zhao, W.W. Yang, J. Power Sources 178 (2008) 291-308.

[18] R. Chen, T.S. Zhao, W.W. Yang, C. Xu, J. Power Sources 175 (2008) 276-287.

[19] G.M. Andreadis, A.K.M. Podias, P.E. Tsiakaras, ]. Power Sources 181 (2008) 214-227.

[20] S. Song, W. Zhou, Z. Liang, R. Cai, G. Sun, Q. Xin, V. Stergiopoulos, P. Tsiakaras Appl. Catal. B: Environ. 55 (2005) 65-72.

[21] J.Szargut, D.R. Morris, F.R. Steward, Exergy Analys is of Thermal, Chemical, and Metallurgical Processes, Springer-Verlag, New York [etc.], 1988.

[22] The Exergoecology Portal. Available from: http://www.exergoecology.com/. 